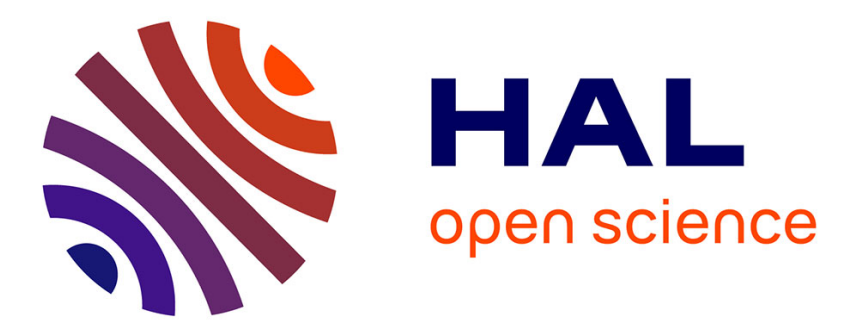

\title{
N2-broadening coefficients of methyl chloride at room temperature
}

Cédric Bray, David Jacquemart, Jeanna Buldyreva, Nelly Lacome, Agnes

Perrin

\section{To cite this version:}

Cédric Bray, David Jacquemart, Jeanna Buldyreva, Nelly Lacome, Agnes Perrin. N2-broadening coefficients of methyl chloride at room temperature. Journal of Quantitative Spectroscopy and Radiative Transfer, 2012, 113 (11), pp.1102-1112. 10.1016/j.jqsrt.2012.01.028 . hal-00746010

\section{HAL Id: hal-00746010 https://hal.sorbonne-universite.fr/hal-00746010}

Submitted on 29 Oct 2012

HAL is a multi-disciplinary open access archive for the deposit and dissemination of scientific research documents, whether they are published or not. The documents may come from teaching and research institutions in France or abroad, or from public or private research centers.
L'archive ouverte pluridisciplinaire HAL, est destinée au dépôt et à la diffusion de documents scientifiques de niveau recherche, publiés ou non, émanant des établissements d'enseignement et de recherche français ou étrangers, des laboratoires publics ou privés. 


\title{
$\mathbf{N}_{2}$-broadening coefficients of methyl chloride at room temperature
}

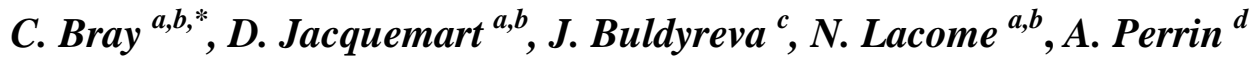 \\ a UPMC Univ Paris 06, Laboratoire de Dynamique, Interactions et Réactivité, UMR 7075, \\ Case Courrier 49, 4 Place Jussieu, 75252 Paris Cedex 05, France \\ ${ }^{\text {b }}$ CNRS, UMR 7075, Laboratoire de Dynamique, Interactions et Réactivité, Case Courrier 49, \\ 4 Place Jussieu, 75252 Paris Cedex 05, France \\ c Institut UTINAM, UMR CNRS 6213, Université de Franche-Comté, 16 Route de Gray, \\ 25030 Besançon cedex, France \\ ${ }^{\mathrm{d}}$ Laboratoire Interuniversitaire des Systèmes Atmosphériques, LISA-UMR7583, CNRS and \\ Universités Paris Est Créteil (UPEC) and Paris Diderot- Paris 7, \\ 61 avenue du Général de Gaulle, 94010 Créteil cedex, France
}

Number of Figures: 9

Number of Tables: 5

Please send proofs to: Bray Cédric

* corresponding author : Cédric Bray (Email: bray@spmol.jussieu.fr)

Tel. 33 (0)1 44273682 - Fax: 33 (0)1 44273021

Keywords : methyl chloride; $v_{1}$ band; pure rotational band; High-resolution Fourier Transform spectra; $\mathrm{N}_{2}$-broadening coefficients; room temperature; $J$ and $K$ dependences; semi-classical approach. 


\section{Abstract}

Methyl chloride is of interest for atmospheric applications, since this molecule is directly involved in the catalytic destruction of ozone in the lower stratosphere. In a previous work [Bray et al. JQSRT 2011;112:2446], lines positions and intensities of self-perturbed ${ }^{12} \mathrm{CH}_{3}{ }^{35} \mathrm{Cl}$ and ${ }^{12} \mathrm{CH}_{3}{ }^{37} \mathrm{Cl}$ have been studied into details for the $3.4 \mu \mathrm{m}$ spectral region. The present work is focused on measurement and calculation of $\mathrm{N}_{2}$-broadening coefficients of the ${ }^{12} \mathrm{CH}_{3}{ }^{35} \mathrm{Cl}$ and ${ }^{12} \mathrm{CH}_{3}{ }^{37} \mathrm{Cl}$ isotopologues. High-resolution Fourier Transform spectra of $\mathrm{CH}_{3} \mathrm{Cl}-\mathrm{N}_{2}$ mixtures at room-temperature have been recorded between 2800 and $3200 \mathrm{~cm}^{-1}$ at LADIR (using a classical source) and between 47 and $59 \mathrm{~cm}^{-1}$ at SOLEIL (using the synchrotron source on the AILES beamline). 612 mid-infrared transitions of the $v_{1}$ band and 86 far-infrared transitions of the pure rotational band have been analyzed using a multispectrum fitting procedure. Average accuracy on the deduced $\mathrm{N}_{2}$-broadening coefficients has been estimated to $5 \%$ and $10 \%$ in the mid- and far-infrared spectral regions, respectively. The $J$ - and $K$-rotational dependences of these coefficients have been observed in the mid-infrared region and then a simulation has been performed using an empirical model for $0 \leq J \leq 50, K \leq 9$. The ${ }^{12} \mathrm{CH}_{3}{ }^{35} \mathrm{Cl}-\mathrm{N}_{2}$ line widths for $0 \leq J \leq 50$ and $K \leq 10$ of the $v_{1}$ band and for $55 \leq J \leq 67$ and $K \leq 15$ of the pure rotational band have been computed using a semiclassical approach involving exact trajectories and a real symmetric-top geometry of the active molecule. Finally, a global comparison with the experimental and theoretical data existing in the literature has been performed. Similar $J$ - and $K$-rotational dependences appeared while no clear evidence for any vibrational and isotopic dependences have pointed out. 


\section{Introduction}

Methyl chloride $\left(\mathrm{CH}_{3} \mathrm{Cl}\right)$ is a trace gas with a tropospheric concentration of about 550 parts per trillion per volume [1] and a total atmospheric lifetime of about 1.2 year [2]. Methyl chloride is one of the most abundant chlorine-containing molecules in the atmosphere with oceans and biomass burning as major natural identified sources [3,4]. The overall uncertainties in $\mathrm{CH}_{3} \mathrm{Cl}$ quantities from these major sources are relatively large [1]. The first infrared detection of the $v_{1}$ band of methyl chloride (3.4 $\mu$ m region) has been performed in 1985 by the ATMOS Fourier-transform spectrometer onboard Spacelab 3 [5]. More recently solar occultation measurements performed by the ACE-FTS experiment on the SCISAT-1 satellite [6] have been used to obtain the first global distribution of methyl chloride in the upper troposphere and lower stratosphere. To improve the spectroscopic retrieval of $\mathrm{CH}_{3} \mathrm{Cl}$ in the atmosphere, the laboratory spectroscopic parameters have to be improved.

In a previous paper focused on the $3.4 \mu \mathrm{m}$ spectral region [7], positions and intensities ${ }^{12} \mathrm{CH}_{3}{ }^{35} \mathrm{Cl}$ and ${ }^{12} \mathrm{CH}_{3}{ }^{37} \mathrm{Cl}$ lines have been studied. The present work is dedicated to the study of the $\mathrm{N}_{2}$-broadening coefficients. In order to analyze the $J$ - and $K$-rotational dependences, a large set of 612 measurements in the $v_{1}$ band around $3.4 \mu \mathrm{m}$ has been performed at room temperature corresponding to various $J$ and $K$ quantum numbers $(J \leq 50, K \leq 9)$. The FT spectrometer of LADIR has been used to study both the $\mathrm{CH}_{3}{ }^{35} \mathrm{Cl}$ and $\mathrm{CH}_{3}{ }^{37} \mathrm{Cl}$ isotopologues. A multispectrum fitting procedure using 7 experimental spectra recorded at various partial pressures of $\mathrm{CH}_{3} \mathrm{Cl}$ and $\mathrm{N}_{2}$ allowed the retrieval of $\mathrm{N}_{2}$-broadening coefficients. The experimentally observed $J$-and $K$-dependences have been modeled using a second-order polynomial function. FT spectra of $\mathrm{CH}_{3} \mathrm{Cl}-\mathrm{N}_{2}$ mixtures have also been recorded in the pure rotational region using the AILES beamline of the synchrotron SOLEIL. $86 \mathrm{~N}_{2}$-broadening coefficients have been deduced for $J \geq 55$ and $K \leq 12$. However, due to the weak dependence of the line widths for such transitions, an average value for the $\mathrm{N}_{2}$-broadening coefficients has been obtained. Finally, the nitrogen-broadening coefficients for the experimentally studied transitions have been computed using a semi-classical approach [8].

Measurements and calculations of $\mathrm{N}_{2}$-broadening coefficients have been previously performed for $\mathrm{CH}_{3} \mathrm{Cl}$ in the $v_{3}$ band around $730 \mathrm{~cm}^{-1}$ [9-12]. The experimental spectra have been recorded using a diode laser spectrometer which allows recording of spectra with a high signal-to-noise ratio but only for a small spectral range. Only 29 transitions have been retrieved corresponding to a reduced range of $J$ and $K$ values. These measurements have then been compared to a semiclassical impact calculation based upon the Anderson-Tsao-Curnutte 
formalism [13]. This theoretical calculation predicted a strong $K$ dependence that could not have been totally confirmed due to the reduced number of measured data.

More recently, experimental and theoretical studies of the $\mathrm{N}_{2}$-broadenig coefficients in the pure rotational spectral region have been completed by Colmont et al. [14] and by Guinet et al. [8]. In Ref. [14], measurements and calculations are presented for the $J=14 \leftarrow 13$ transitions focusing on the $K$ dependence. In Ref. [8], two experimental setups (frequencymodulation chain and continuous-wave photomixing spectrometer) have been used to record the rotational lines located between $186 \mathrm{GHz}$ and $1.346 \mathrm{THz}(6 \leq J \leq 50$ and $K \leq 18)$. $\mathrm{N}_{2}$ broadening coefficients have been retrieved for 84 transitions, and a semi-classical calculation has been done using exact trajectories, an interaction potential including short-range forces, and a rigorous treatment of the active molecule as a symmetric top. In this study the $J$ and $K$ dependences of the $\mathrm{N}_{2}$-broadening coefficients have been clearly observed and successfully reproduced by calculation.

In next Section the experimental conditions are presented for spectra recorded at LADIR and SOLEIL. Then, the retrieved broadening coefficients are presented in Section 3. The analysis of the measurements including an empirical modeling and a theoretical calculation is given in Section 4. Finally Section 5 is dedicated to a comparison of the present results with those from the literature.

\section{Experimental conditions}

Two different sets of experimental spectra have been recorded using high resolution Fourier-transform spectrometers, one in the mid-infrared region around $3.4 \mu \mathrm{m}$ and the other in the far-infrared region around $55 \mathrm{~cm}^{-1}$. To achieve the best signal-to-noise ratio in these two spectral regions, the first set of spectra has been recorded at LADIR with a globar source, whereas the second set has been recorded using the AILES beamline of the synchrotron SOLEIL. The experimental conditions of each set of spectra are described in the following sub-sections. In both cases, the average interferograms has been Fourier transformed using the procedure included in the Bruker OPUS package, selecting a Mertz phase error correction. The spectra have not been numerically apodized.

\subsection{Spectra recorded at LADIR around $3.4 \mu \mathrm{m}$}


Around $3.4 \mu \mathrm{m}, 7$ Fourier-transform spectra have been recorded using the rapid scan Bruker IFS $120 \mathrm{HR}$ interferometer of LADIR. The experimental conditions are summarized in Table 1. The interferometer has been equipped with a $\mathrm{CaF}_{2}$ beam splitter, an InSb detector and a globar source. All spectra have been recorded near the room temperature. The temperature has been measured using four platinum probes located at different places inside the cell. The accuracy of the average temperatures given in Table 1 is around $\pm 0.5 \mathrm{~K}$. A multi-pass White-type cell (1 m base length) with an absorption path of $415 \mathrm{~cm}$ has been used. For these LADIR spectra (\#1 to \#7, see Table 1), since no optical filter has been used, the whole 1800-5000 $\mathrm{cm}^{-1}$ spectral range has been recorded. Therefore, $\mathrm{CO}_{2}$ and $\mathrm{H}_{2} \mathrm{O}$ transitions, coming from impurities present in the interferometer, have been used to perform the wavenumber calibration (see Section 3.1). The commercial methyl chloride and $\mathrm{N}_{2}$ gases, furnished by Alpha Gaz with a stated purity of $99.9 \%$ in natural abundance, were used without any further purification. Pressures of gases have been measured with 4 Baratron gauges with accuracy better than $\pm 0.15 \%$ for the 1 mbar full scale gauge and better than $\pm 0.25 \%$ for the 100 and 1000 mbar full scale gauges. A weak multiplicative channel spectrum, due to the windows of the cell, has been observed in all experimental spectra. Its period is around $0.60 \mathrm{~cm}^{-1}$ with maximum peak to peak amplitude less than $2 \%$. Because the adjusted spectral domains used in this study are always narrower than the half-period of the channel, this channel spectrum can be reproduced by using a polynomial expansion that adjusts the continuous background.

\subsection{Spectra recorded at SOLEIL in the pure rotational region}

Four spectra have been recorded with the rapid scan Bruker IFS 125 HR interferometer of the SOLEIL/AILES beamline. Experimental conditions for these spectra (\#8 to \#11) are gathered in Table 1. For high-resolution measurements, the use of a synchrotron source was necessary to achieve a satisfactory signal-to-noise ratio in the pure rotational region. The interferometer has been equipped with a $6 \mathrm{~mm}$ Mylar beam splitter, a $4.2 \mathrm{~K}$ Si-Bolometer detector and an optical filter covering the spectral region between 0 and $250 \mathrm{~cm}^{-1}$. The entire AILES beamline has been used without any aperture stop in order to obtain the maximum signal-to-noise ratio. The optical weighting due to the size of the beam inside the interferometer will be studied in Section 3.2. The whole optical path was maintained under 
vacuum and a multipass White-type cell (2.5 m base length) has been aligned to provide a (10.14 \pm 0.01$) \mathrm{m}$ absorption path length. The cell has been equipped with 50 -mm-thick polypropylene windows and the temperature of the gas in the cell has been obtained by averaging measurements performed in the room at different times, so that the uncertainty on the temperature has been estimated to be around $\pm 1 \mathrm{~K}$. Pressures inside the cell have been measured using two MKS Baratrons (1- and 10-mbar full scale range manometers) with an accuracy better than $\pm 0.25 \%$. The signal-to-noise ratio of the average spectra depends on the wavenumber and was about 25 in the rotational band around $60 \mathrm{~cm}^{-1}$. As it can be observed in Fig. 1, a significant irregular multiplicative channel (with maximum peak to peak amplitude around 30\%) spectrum was present in all spectra. This channel spectrum has been modeled locally as a background adjusted on a small spectral range of around $0.14 \mathrm{~cm}^{-1}$ with a second-order polynomial function. As a comparison (see Fig. 1), the experimental spectra recorded in LADIR do not contain a such significant and irregular multiplicative channel spectrum.

\section{Preliminary treatments and measurements of $\mathbf{N}_{2}$-broadening coefficients}

To analyze the spectra recorded both at LADIR and at SOLEIL, a preliminary treatment has been performed in order to deduce accurate $\mathrm{N}_{2}$-brodening coefficients. It concerns mainly the optical weighting due to the size of the beam that affects the apparatus function (not negligible with Fourier transform spectrometers). Moreover a wavenumber calibration has been done for each set of spectra.

\subsection{Preliminary treatment of LADIR spectra}

For each spectrum, the apparatus function has been calculated performing numerically the Fourier transform of the interferograms, taking into account the effect of the throughput and of the finite optical path difference [15]. In the definition of the apparatus function, the aperture (nominal value equal to $0.75 \mathrm{~mm}$ ) and the focal length of the collimator $(418 \mathrm{~mm})$ are sensitive parameters. Since the effect of the beam size on the apparatus function is more sensitive on spectra \#1 and \#2, the effective iris radius has been fitted on isolated transitions in these spectra. The average effective iris radius has been obtained using $\mathrm{CH}_{3} \mathrm{Cl}, \mathrm{H}_{2} \mathrm{O}$ and $\mathrm{CO}_{2}$ transitions and has been found equal to $(0.80 \pm 0.04) \mathrm{mm}$ for the 90 fitted transitions. The effect on the line parameters retrievals is not negligible even if this average value is close to the nominal one. For example, for the transition at $2961.9511 \mathrm{~cm}^{-1}$ with an intensity of 
$4.46 \times 10^{-21} \mathrm{~cm}^{-1} /\left(\right.$ molecule.cm $\left.{ }^{-2}\right)$, the $\mathrm{N}_{2}$-broadening coefficient is $2 \%$ higher when using a value of aperture equal to $0.80 \mathrm{~mm}$ instead of $0.75 \mathrm{~mm}$.

Concerning the wavenumber calibration, absolute wavenumbers from HITRAN [15] have been used for isolated transitions of $\mathrm{CO}_{2}$ near $2300 \mathrm{~cm}^{-1}$ and $\mathrm{H}_{2} \mathrm{O}$ near 1900 and 3900 $\mathrm{cm}^{-1}$. Taking into account the accuracy of positions in HITRAN and the precision on the present measurements, the absolute accuracy on line positions has been estimated between $0.1 \times 10^{-3}$ and $1 \times 10^{-3} \mathrm{~cm}^{-1}$.

\subsection{Preliminary treatment of SOLEIL spectra}

In the case of the AILES beamline at SOLEIL synchrotron, the entire beam is injected into the interferometer, and the beam size depends on the wavenumber in contrast with classical sources. The knowledge of the beam size is important to calculate accurately the apparatus function. This is necessary to extract accurate broadening parameters. In the following, the beam has been considered as limited by an iris of radius $R$ to be determined as a fitted parameter. For spectra obtained in this work, since the full width at half maximum (FWHM) of the apparatus function $\left(0.002 \mathrm{~cm}^{-1}\right)$ is of the same order of magnitude as the FWHM of the lines (between 0.002 and $0.004 \mathrm{~cm}^{-1}$ ), the effect of the optical weighting on the apparatus function cannot be neglected. However, in order to better determine the effective radius of the beam, spectra \#8 has been chosen to fit this parameter. Indeed, the collisional width of the transitions is the weakest in spectrum \#8, so that the effect of the apparatus function is well observable and adjustable. 24 isolated transitions of water between 59 and $211 \mathrm{~cm}^{-1}$ (present as trace in the cell) have been selected. Their intensities have been fitted together with the effective beam radius parameter in the spectrum \#8. This preliminary study allowed firstly, to estimate the effective value of the size of the beam, but also to perform an absolute wavenumber calibration using as reference the line positions given in the HITRAN database [16] (line positions coming from Ref. [17]).

Previous studies $[18,19]$ on the AILES beamline have been performed and the results concerning the radius values in the present work are compared in Fig. 2 to what has been found previously [19]. As it can be seen on this figure, there is a good agreement between the wavenumber dependence of the effective radius of the beam obtained from this work and the previous studies. Moreover, the effective radius of the beam obtained is always higher than the calculation using SOLEMIO and SRW models [20]. This dependence has been modeled with a polynomial function that reproduces such dependence inside the studied spectral range (50-100 $\mathrm{cm}^{-1}$ ). In the next step of this work, the broadening parameters have been fitted using, 
for the optical weighting of the apparatus function, the values of the radius of the beam deduced from the polynomial function. In the 50-100 $\mathrm{cm}^{-1}$ spectral range, since the wavenumber dependence on the size of the beam is very strong, neglecting it will lead to erroneous measurements for the line parameters.

\section{2. $\mathrm{N}_{2}$-broadening coefficients measurements}

A multispectrum fitting procedure [21] has been used to adjust simultaneously the profiles of the transitions in spectra \#1-7 and in spectra \#8-11 for retrieving the $\mathrm{N}_{2^{-}}$ broadening coefficients in the $3.4 \mu \mathrm{m}$ region and in the pure rotational region. Since methyl chloride has a large dipole moment, the effect of the self broadening on the line profiles is significant [22-23] and a low pressure of methyl chloride has been used to minimize perturbations in the measurement of the $\mathrm{N}_{2}$-broadening coefficients. Note that due to the strong overlapping of $\mathrm{CH}_{3} \mathrm{Cl}$ transitions and to the presence of both $\mathrm{CH}_{3}{ }^{35} \mathrm{Cl}$ and $\mathrm{CH}_{3}{ }^{37} \mathrm{Cl}$ isotopologues, the higher pressure of $\mathrm{N}_{2}$ in the cell was constrained to 120 mbar for spectra \#1-7 and to 16 mbar for spectra \#8-11. For the broadening coefficients, we assumed that the effects of collisions for $\mathrm{CH}_{3}{ }^{35} \mathrm{Cl}$ and $\mathrm{CH}_{3}{ }^{37} \mathrm{Cl}$ are similar, so that the broadening coefficients can be written:

$$
\begin{gathered}
\gamma_{\mathrm{CH}_{3}{ }^{35} \mathrm{C} / \mathrm{CH}_{3}{ }^{35} \mathrm{Cl}}=\gamma_{\mathrm{CH}_{3}{ }^{37} \mathrm{Cl} / \mathrm{CH}_{3}{ }^{37} \mathrm{Cl}}=\gamma_{\mathrm{CH}_{3}{ }^{37} \mathrm{Cl} \mathrm{CH}_{3}{ }^{35} \mathrm{Cl}}=\gamma_{\mathrm{CH}_{3}{ }^{35} \mathrm{Cl} / \mathrm{CH}_{3}{ }^{37} \mathrm{Cl}}=\gamma_{\text {self }}, \\
\gamma_{\mathrm{CH}_{3}{ }^{35} \mathrm{Cl} / \mathrm{N}_{2}}=\gamma_{\mathrm{CH}_{3}{ }^{37} \mathrm{Cl} / \mathrm{N}_{2}}=\gamma_{\mathrm{N}_{2}} .
\end{gathered}
$$

No temperature correction has been done, since temperatures of all spectra are close to 296K. For all transitions, a Voigt profile has been used and no systematic deviation from this profile has been observed in the residuals for all spectra. Figure 3 gives an example of a fit in the 3.4 $\mu \mathrm{m}$ spectral region and the pure rotational region. Residuals obtained for fits in the $3.4 \mu \mathrm{m}$ spectral region are lesser than $1 \%$ due to the high signal-to-noise ratio. In the pure rotational region, residuals can exceed 5\% due to the low signal-to-noise ratio. In pure rotational region, the transitions for $K=0$ and 1 are overlapped. To obtain a fit of the $J$-branches, a simple transition has been taken into account for these two overlapped transitions. This explains the high residual observed on the low $K$ values of the $J$-branches. This effect is less important more the pressure of gas is important. Taking into account the relatively high pressure of $\mathrm{N}_{2}$ used for spectra around $3.4 \mu \mathrm{m}$ and the signal-to-noise ratio obtained in this region (see Table 1), the average accuracy on $\mathrm{N}_{2}$-broadening coefficients measurements has been estimated to be around 5\%. For the pure rotational region, taking into account the signal-to-noise ratio (see 
Table 1) and the lower $\mathrm{N}_{2}$ pressures, the average accuracy on $\mathrm{N}_{2}$-broadening coefficients measurements has been estimated to be around $10 \%$.

In the $3.4 \mu \mathrm{m}$ spectral region, 612 measurements of $\mathrm{N}_{2}$-broadening coefficients have been obtained for large set of $J$ and $K$ values ( $J$ from 0 up to 40 , and $K$ from 0 up to 9). These results have been used to adjust an empirical model described in Section 4.1. In the pure rotational region, 86 measurements have been performed for high $J$ values ( $J$ higher than 55 ) and for $K$ values between 0 and 12. However, due to the weak dependence of the line widths on $J$ and $K$ observed for $J \geq 55$ and $K \leq 12$, an average value for the $\mathrm{N}_{2}$-broadening coefficients has been obtained for transitions with $J \geq 55$.

\section{Analysis and theoretical calculation}

\subsection{Analysis of the measurements using an empirical model}

Extensive measurements of $\mathrm{N}_{2}$-broadening coefficients, obtained for a large scale of $J$ and $K$ values, allowed the study of the rotational dependences (in $J$ and $K$ ) of broadening coefficients. This large scale of measurements describing the $J$ and $K$ dependences confirmed and clarified the trend of previous works [9-12].

For $\mathrm{C}_{3 v}$ molecules, in the study of Jacquemart et al. [24] on $\mathrm{CH}_{3} \mathrm{Br}$, an empirical model has been used to reproduce the rotational dependence of the large set of broadening coefficients measured for various $J$ and $K$ values. In the present work, the same model has been employed to analyze the measurements of $\mathrm{N}_{2}$-broadening coefficients of $\mathrm{CH}_{3} \mathrm{Cl}$.

For each set of transitions with the same $J$ value, the $\mathrm{N}_{2}$-broadening coefficients have been fitted with a polynomial expansion of order two in $K$ (fixing the first-order term to zero):

$$
\gamma_{N_{2} \text { emp }}(K)=a_{J}^{0}+a_{J}^{2} K^{2} .
$$

An example of these fits is given in Fig. 4 for transitions with $J=4,10,19$, and 28. Due to the small number of measurements for $J>38$, the coefficients $a_{J}^{0}$ and $a_{J}^{2}$ have been obtained only for $J \leq 38$. The coefficients $a_{J}^{0}$ and $a_{J}^{2}$ obtained for each set of same $J$ value have been plotted versus $J$ in Figs. 5 and 6 respectively. The parameter $a_{J}^{2}$ represents the $K$ dependence of the broadening coefficients having the same $J$ value. This dependence is maximum when $J$ is equal to $K$. In the present work, the $K$ dependence begins to be observable when $K \geq J / 2$. Taking into account that measurements are obtained only for transitions with $K$ up to 9 , the $\mathrm{K}$ 
dependence is clearly observed in Fig. 4 only for set of $J$ values up to 18. For transitions with $J$ higher than 20, the observed $K$ dependence is weak since no transition with $K$ values higher than 9 was observed. The fitted parameters $a_{J}^{0}$ and $a_{J}^{2}$ have been smoothed to allow to calculate the $\mathrm{N}_{2}$-broadening coefficients for any value of $J$ and $K$. Using this model, the $K$ dependence is plotted in Fig. 7 versus $J$ for $K$ ranging from 0 to 9. The fitted and smoothed values of $a_{J}^{0}$ and $a_{J}^{2}$ parameters are summarized in Table 2. The calculated $\mathrm{N}_{2}$-broadening coefficients using this model and the smoothed values of Table 2 are given in supplementary data together with experimental values (see Section 5).

\subsection{Theoretical calculation}

Since no isotopic dependence has been observed for ${ }^{12} \mathrm{CH}_{3}{ }^{35} \mathrm{Cl}$ and ${ }^{12} \mathrm{CH}_{3}{ }^{37} \mathrm{Cl}$, the theoretical calculation of $\mathrm{N}_{2}$-broadening coefficients has been performed only for the ${ }^{12} \mathrm{CH}_{3}{ }^{35} \mathrm{Cl}$ isotopologue. The semi-classical calculation has been done using the formalism developed in Ref. [25] for symmetric-top active molecules of $\mathrm{CH}_{3} \mathrm{X}$-type colliding with nonpolar diatomics $\mathrm{Y}_{2}$ involving exact trajectories. The intermolecular interaction potential $\mathrm{CH}_{3} \mathrm{Cl}-\mathrm{N}_{2}$ has been taken as described in Ref. [8], and the rotational constants used for the ground $\left(A_{0}\right.$ and $\left.B_{0}\right)$ and excited $v_{1}\left(A_{1}\right.$ and $\left.B_{1}\right)$ vibrational states of the active molecule are those of Ref. [7]: $A_{0}=5.2053361 \mathrm{~cm}^{-1}, \quad B_{0}=0.44340278 \mathrm{~cm}^{-1}, \quad A_{1}=5.149695 \mathrm{~cm}^{-1}$, $B_{1}=0.4430333 \mathrm{~cm}^{-1}$. In order to perform a comparison with the measurements from the present work, the $\mathrm{N}_{2}$-broadening coefficients have been calculated both for the $v_{1}$ and pure rotational transitions. Calculated values for transitions of the $v_{1}$ band with $0 \leq J \leq 50$ and $K \leq 10$, and for pure rotational transitions with $51 \leq J \leq 70$ and $K \leq 15$ are given in supplementary materials and have been used for the comparison presented in Section 5. A sample of comparison between the calculations for the pure rotational and the $v_{1}$ bands is given in Table 3 for transitions with $K$ equal to 3 and $J$ less than 40. This comparison shows that there is no significant difference between the results obtained for the two bands (difference smaller than $2 \times 10^{-5} \mathrm{~cm}^{-1}$.atm ${ }^{-1}$ ). Such a deviation could not be observable from measurements. Consequently, the vibrational dependence of the $\mathrm{N}_{2}$-broadening coefficients can be neglected for $\mathrm{CH}_{3} \mathrm{Cl}$.

\section{Comparison}


Comparisons between measurements and calculations have been performed both for transitions of the $v_{1}$ band and transitions of the pure rotational band. Moreover, comparisons with measurements and calculations available in the literature at $296 \mathrm{~K}$ have been included.

For transitions with $J$ less than 50, our measurements in the $v_{1}$ band (for 612 transitions) can be compared to the values calculated in Sections 4.1 and 4.2. Table 4 gives a sample of such comparison. The complete version of this table is available as supplementary materials. Moreover, the measurements obtained for the $v_{1}$ band can be compared to the measurements of Refs. [9-12] obtained in the $v_{3}$ band (for 29 transitions), and to those of Ref. [8] in the pure rotational band (for 84 transitions). Figure 8 shows such a comparison between experimental measurements together with the empirical model presented in Section 4.1, the theoretical calculation presented in Section 4.2, and the theoretical calculations of Ref. [9]. The general trend for the $J$ - and $K$-rotational dependences of the $\mathrm{N}_{2}$-broadening coefficients is similar for all measurements and calculations: i.e. a decreasing of the widths for a same $J$ value with increasing $K$ (as observed in Fig. 7). Moreover, for $K$ values close to those of $J$, we observed both for measurements and calculations the decreasing of the widths. This trend is enhanced when $K$ is increasing. The maximal average deviation between the various measurements or calculations presented in Fig. 8 does not exceed 5\%, except for the transitions with $K=9$ but the intensities of these transitions are very weak. This seems to indicate that the $\mathrm{N}_{2}$-broadening coefficients of $\mathrm{CH}_{3} \mathrm{Cl}$ do not present a significant vibrational dependence, confirming the very good consistency between the theoretical calculations presented in Section 4.2 for the $v_{1}$ and pure rotational band (see Table 3). In general, a good consistency is observed between our results and those from the literature. However, it can be observed that for high $J$ values, our measurements seem to be systematically slightly higher than those from Ref. [8] but in our spectra these transitions are weak. Note that measurements in submillimeter and terahertz regions from Ref. [8] are more accurate than in the infrared region since the strong line overlapping existing in the $3.4 \mu \mathrm{m}$ spectral region is avoided. It is also important to stress that the various measurements have been obtained with different techniques: Fourier transform spectroscopy in our study, tunable diode laser for Ref. [9-12], and a frequency-modulation chain and continuous-wave photomixing spectrometer for Ref. [8]. The agreement between theoretical calculations and measurements is very satisfactory. There is also a good agreement between the theoretical and empirical calculation, except for high $K$ values $(K \geq 7)$ for which the difference is probably due to the lack of accurate measurement obtained for such $K$ values. 
For transitions with $J$ greater than 55, no measurements has been found in the literature, so that our measurements performed using the SOLEIL synchrotron can only been compared to the theoretical calculation of Section 4.1. The comparison is presented in Fig. 9 versus $J$. First of all, we can notice the strong scattering of the measurements performed using spectra recorded in SOLEIL for transitions with $J \geq 55$ and $K$ ranging from 0 to 12. This scattering is due to the very low signal-to-noise ratio (20 to 50) and to the strong overlapping of the transitions. Since the maximum $K$ value is only equal to 15 for transitions with $J \geq 55$, no K-rotational dependence can be observed. For that reason all measurements have been plotted in Fig. 9 with the same symbol for all $K$ values. Consequently, an average value equal to $(0.092 \pm 0.009) \mathrm{cm}^{-1}$.atm ${ }^{-1}$ has been obtained. This value is coherent with the experimental measurements from Ref. [8] at $J$ equal 50 (see Fig. 8). A sample of the experimental measurements performed at SOLEIL is given in Table 5 (the complete Table is available as supplementary material). The semi-classical calculations performed for $J=50-70$ are almost identical for $K$ equal to 0 and 15 (see Fig. 9) and close to the average value of $0.092 \mathrm{~cm}^{-1}$.atm ${ }^{1}$, confirming the weak $K$-rotational dependence for the set of studied transitions.

\section{Conclusion}

Using a multispectrum fitting procedure, 612 measurements of $\mathrm{N}_{2}$-broadening coefficients of methyl chloride have been performed in the $3.4 \mu \mathrm{m}$ region ( $v_{1}$ band) at room temperature. An empirical model and semi-classical calculations have allowed reproducing the $J$-and $K$ rotational dependences of these measurements. Comparisons with the results existing in the literature show a good agreement and confirm the $J$-and $K$-rotational dependences of our experimental data. The proposed empirical model enables a good prediction of broadening coefficients when no theoretical results are available. If necessary, a reliable prediction of line widths can be obtained by the semi-classical method used in the present work. These calculations demonstrate also a good agreement with the measurements for the pure rotational band realized on the Synchrotron SOLEIL, which ensures the possibility to predict the $\mathrm{N}_{2}$ broadening coefficients for any $\mathrm{CH}_{3} \mathrm{Cl}$ transitions with an accuracy estimated to be around $5 \%$ for transitions with $J$ up to 70 and $K$ up to 10 . The global analysis of experimental and 
theoretical results argues in favor of no significant isotopic and vibrational dependences of $\mathrm{CH}_{3} \mathrm{Cl}-\mathrm{N}_{2}$ line broadening coefficients.

\section{Acknowledgments}

The authors thank M. Guinet and F. Rohart for making available their results before

publication, and O. Pirali and M.A. Martin for their help during the recording of the spectra using the AILES beamline at SOLEIL. 


\section{References}

[1] Fraser SA, Frase PJ, Butler JH, Connell PS, Cunnold DM, Daniel JS, Derwent RG, Lal S, McCulloch A, Oram DE, Reeves CE, Sanhueza E, Steele LP, Velders GJM, Weiss RF, Zander RJ. Controlled substances and other source gases. Chapter 1 in Scientific Assessment of Ozone Depletion: 2002, Global Ozone Research and Monitoring Project—Report No. 47, World Meteorological Organization, Geneva (2003).

[2] Yoshida Y. Global sources and distribution of atmospheric methyl chloride. thesis (2006).

[3] Khalil MAK, Moore RM, Harper DB, Lobert JM, Erickson DJ, Koropalov V, Sturges WT, Keene WC. Natural emissions of chlorine-containing gases: Reactive Chlorine Emissions Inventory. J. Geophys. Res., 1999;104:8333-46.

[4] Keene WC, Khalil MAK, Erickson III DJ, McCulloch A, Graedel TE, Lobert JM, Aucott ML, Gong SL, Harper DH, Kleiman G, Midgley P, Moore RM, Seuzaret C, Sturges WT, Benkovitz CM, Koropalov V, Barrie LA, Li YF. Composite global emissions of reactive chlorine from anthropogenic and natural sources: Reactive Chlorine Emissions Inventory. J. Geophys. Res., 1999;104:8429-40.

[5] Park JH, Zander R, Farmer CB, Rinsland CP, Russell JM, Horton RH, Raper OF, Geophys Res. Letter. 1986;13:765-8.

[6] Kaley AW, Weigum N, McElcheran C, Taylor JR. Global methyl chloride measurements from the ACE-FTS instrument. International Symposium on Molecular Spectroscopy Department of Chemistry The Ohio State University, TI-09; 2009.

[7] Bray C, Perrin A, Jaquemart D, Lacome N. The $v_{1}, v_{4}$ and $3 v_{6}$ bands of methyl chloride in the 3.4 $\mu \mathrm{m}$ region: line positions and intensities. JQSRT 2011;112:2446-62.

[8] Guinet M, Rohart F, Buldyreva J, Gupta V, Eliet S, Motiyenko R, Margulès L, Cuisset A, Hindle F, Mouret G. Experimental studies by complementary terahertz techniques and semiclassical calculations of $\mathrm{N}_{2}$-broadening coefficients of $\mathrm{CH}_{3}{ }^{35} \mathrm{Cl}$. Submitted in this special issue of JQSRT.

[9] Bouanich JP, Blanquet G, Populaire JP, Walrand J. $\mathrm{N}_{2}$-broadening for methyl chloride at low temperature by Diode-laser spectroscopy. J Mol Spectrosc 2001;208:72-8.

[10] Bouanich JP, Blanquet G, Walrand J. Theoretical $\mathrm{O}_{2}$ - and $\mathrm{N}_{2}$-broadening coefficients of $\mathrm{CH} 3 \mathrm{Cl}$ Spectral lines. J Mol Spectrosc 1993;161:416-26.

[11] Blanquet G, Walrand J, Bouanich JP. Diode-laser measurements of $\mathrm{N}_{2}$-broadening coefficients in the $v_{3}$ band of $\mathrm{CH}_{3}{ }^{35} \mathrm{Cl}$. J Mol Spectrosc 1993;160:253-7.

[12] Blanquet G, Coupe P, Walrand J, Bouanich JP. Determination of broadening coefficients and intensities for overlapping spectral lines with application to the ${ }^{Q} R(3, K)$ lines in the $v_{3}$ band of $\mathrm{CH}_{3}{ }^{35} \mathrm{Cl}$. JQSRT 1994;51:671-8.

[13] Tsao CJ, Curnutte B. Lines-widths of pressure-broadened spectral lines. JQSRT 1962;2:41-91.

[14] Colmont JP, Rohart F, Wlodarczak G, Bouancih JP. K-dependence and temperature dependence of $\mathrm{N}_{2}$ - and $\mathrm{O}_{2}$-broadening coefficients for the $\mathrm{J}=14-13$ transition of methyl chloride $\mathrm{CH}_{3}{ }^{35} \mathrm{Cl}$. $\mathrm{J}$ Mol Struct 2006;780-781:268-76.

[15] Dana V, Mandin JY. New improvements in the determination of line parameters from FTS data. JQSRT 1992;4:725-31. 
[16] Rothman LS, Gordon IE, Barbe A, Benner DC, Bernath PF, Birk M, Boudon V, Brown LR, Campargue A, Champion JP, Chance K, Coudert LH, Dana V, Devi VM, Fally S, Flaud JM, Gamache RR, Goldmanm A, Jacquemart D, Kleiner I, Lacome N, Lafferty QJ, Mandin JY, Massie ST, Mikhailenko SN, Miller CE, Moazzen-Ahmadi N, Naumenko OV, Nikitin AV, Orphal J, Perevalov VI, Perrin A, Predoi-Cross A, Rinsland CP, Rotger M, Simeckova MS, Smith MAH, Sung K, Tashkun SA, Tennyson J, Toth RA, Vandaele AC, Vander Auwera J. The HITRAN 2008 molecular spectroscopic database, JQSRT 2009;110:533-72.

[17] Lanquetin R, Coudert LH, Camy-Peyret C. High-lying rotational levels of water: an analysis of the energy of the five first vibrational states. J Mol Spectrosc 2001;206: 83-103.

[18] Jacquemart D, Gomez L, Lacome L, Mandin J-Y, Pirali O, Roy P. Measurement of absolute line intensities in the $v_{5}-v_{4}$ band of ${ }^{12} \mathrm{C}_{2} \mathrm{H}_{2}$ using SOLEIL synchrotron far infrared AILES beamline. JQSRT 2010;111:1223-33.

[19] Jacquemart D. Characterization of the synchrotron/AILES beam apparatus function for accurate measurements of acetylene line intensities around $100 \mu \mathrm{m}$. To be submitted.

[20] Roy P, Rouzières M, Qi Z, Chubar O. The AILES Infrared Beam line on the third generation Synchrotron Radiation Facility SOLEIL. Infrared Physics \& Technology 2006;49:139-46.

[21] Jacquemart D, Mandin JY, Dana V, Picqué N, Guelachvili G. A multispectrum fitting procedure to deduce molecular line parameters. Application to the 3-0 band of ${ }^{12} \mathrm{C}^{16} \mathrm{O}$. Eur Phys J D 2001;14:5569.

[22] Bouanich JP, Blanquet G, Walrand J. Diode-laser measurements of self-broadening coefficients and line strength in the $v_{3}$ band of $\mathrm{CH}_{3}{ }^{35} \mathrm{Cl}$. JQSRT 1994;51:573-8.

[23] Chackerian C, Jr, Brown LR, Lacome N, Tarrago G. Methyl Chloride $v_{5}$ Region Lineshape Parameters and Rotational Constants for the $v_{2}, v_{5}$, and $2 v_{3}$ Vibrational Bands. J Mol Spectrosc 1998;191:148-57.

[24] Jacquemart D, Kwabia Tchana F, Lacome N, Kleiner I. A complete set of line parameters for $\mathrm{CH}_{3} \mathrm{Br}$ in the 10- $\mu \mathrm{m}$ spectral region. JQSRT 2007;105:264-302.

[25] Buldyreva J, Guinet M, Eliet S, Hindle F, Mouret G, Bocquet R, Cuisset A. Theoretical and experimental studies of $\mathrm{CH}_{3} \mathrm{X}-\mathrm{Y}_{2}$ rotational line shapes for atmospheric spectra modelling: application to room-temperature $\mathrm{CH}_{3} \mathrm{Cl}-\mathrm{O}_{2}$. Phys. Chem. Chem. Phys., DOI:10.1039/C1CP22232E (2011) 
Table 1: Experimental conditions and characteristics of the recorded spectra

Unapodized apparatus function (for LADIR spectra)

Nominal aperture radius

$0.75 \mathrm{~mm}$

Effective aperture radius

$0.80 \mathrm{~mm}$

Collimator focal length

$418 \mathrm{~mm}$

Absorbing sample

Natural $\mathrm{CH}_{3} \mathrm{Cl} 74.89 \%$ of ${ }^{12} \mathrm{CH}_{3}{ }^{35} \mathrm{Cl}$

$$
23.94 \% \text { of }{ }^{12} \mathrm{CH}_{3}{ }^{37} \mathrm{Cl}
$$

Stated purity

$99.9 \%$

Broadening gas stated purity: 99.9\%

Experimental conditions

$\mathrm{S} / \mathrm{N}$ ratio $\approx 700-1000$ for LADIR spectra (\#1-7)

$\approx 20$-50 for SOLEIL spectra (\#8-11)

\begin{tabular}{lccccc}
\hline$\#$ & $\begin{array}{c}\mathrm{CH}_{3} \mathrm{Cl} \text { pressure } \\
(\mathrm{mbar})\end{array}$ & $\begin{array}{c}\mathrm{N}_{2} \text { pressure } \\
(\mathrm{mbar})\end{array}$ & $\begin{array}{c}\text { Resolution }^{\mathrm{a}} \\
\left(\mathrm{cm}^{-1}\right)\end{array}$ & $\begin{array}{c}\text { Absorption path } \\
(\mathrm{cm})\end{array}$ & $\begin{array}{c}\text { Temperature } \\
(\mathrm{K})\end{array}$ \\
\hline 1 & $0.051_{2}$ & 0 & 0.008 & $415 \pm 1$ & $294.3 \pm 0.5$ \\
2 & $0.104_{4}$ & 0 & 0.008 & $415 \pm 1$ & $293.5 \pm 0.5$ \\
3 & $0.253_{8}$ & 0 & 0.008 & $415 \pm 1$ & $297.0 \pm 0.5$ \\
4 & $0.310_{6}$ & $20.2_{2}$ & 0.02 & $415 \pm 1$ & $295.3 \pm 0.5$ \\
5 & $0.253_{3}$ & $42.0_{8}$ & 0.02 & $415 \pm 1$ & $295.9 \pm 0.5$ \\
6 & $0.270_{3}$ & $68.4_{3}$ & 0.02 & $415 \pm 1$ & $294.8 \pm 0.5$ \\
7 & $0.269_{3}$ & $120.2_{3}$ & 0.02 & $415 \pm 1$ & $295.4 \pm 0.5$ \\
& & & & & \\
8 & $1.00_{3}$ & 0 & 0.002 & $1014 \pm 1$ & $295.4 \pm 1$ \\
9 & $1.00_{8}$ & $6.17_{5}$ & 0.002 & $1014 \pm 1$ & $295.5 \pm 1$ \\
10 & $0.96_{0}$ & $9.89_{0}$ & 0.002 & $1014 \pm 1$ & $295.6 \pm 1$ \\
11 & $1.00_{8}$ & $16.5_{6}$ & 0.002 & $1014 \pm 1$ & $295.6 \pm 1$
\end{tabular}

${ }^{\mathrm{a}}$ Resolution as defined by Bruker $=0.9$ /Maximum optical path 
Table 2: $a_{J}^{0}$ and $a_{J}^{2}$ parameters (in $\mathrm{cm}^{-1} \cdot \mathrm{atm}^{-1}$ ) obtained in this work to reproduce the $J$ and $K$ dependences of the $\mathrm{N}_{2}$-broadening coefficients.

\begin{tabular}{|c|c|c|c|c|}
\hline \multirow[b]{2}{*}{$J$} & \multicolumn{2}{|c|}{$a_{J}^{0}$} & \multicolumn{2}{|c|}{$a_{J}^{2}$} \\
\hline & Fitted values & $\begin{array}{c}\text { Smoothed } \\
\text { values }\end{array}$ & Fitted values & $\begin{array}{c}\text { Smoothed } \\
\text { values }\end{array}$ \\
\hline 0 & --- & 0.1314 & --- & -- \\
\hline 1 & 0.1300 & 0.1312 & $-4.38 \mathrm{E}-03$ & $-4.16 \mathrm{E}-03$ \\
\hline 2 & 0.1304 & 0.1293 & $-2.50 \mathrm{E}-03$ & $-2.75 \mathrm{E}-03$ \\
\hline 3 & 0.1291 & 0.1278 & $-1.57 \mathrm{E}-03$ & $-1.73 \mathrm{E}-03$ \\
\hline 4 & 0.1262 & 0.1265 & $-1.04 \mathrm{E}-03$ & $-1.03 \mathrm{E}-03$ \\
\hline 5 & 0.1252 & 0.1254 & $-6.55 \mathrm{E}-04$ & $-5.65 \mathrm{E}-04$ \\
\hline 6 & 0.1227 & 0.1243 & $-1.25 \mathrm{E}-04$ & $-2.74 \mathrm{E}-04$ \\
\hline 7 & 0.1231 & 0.1232 & $-2.13 \mathrm{E}-04$ & $-1.09 \mathrm{E}-04$ \\
\hline 8 & 0.1232 & 0.1221 & $-1.63 \mathrm{E}-04$ & $-1.05 \mathrm{E}-04$ \\
\hline 9 & 0.1221 & 0.1209 & $-3.07 \mathrm{E}-04$ & $-1.02 \mathrm{E}-04$ \\
\hline 10 & 0.1198 & 0.1197 & $-2.26 \mathrm{E}-04$ & $-9.80 \mathrm{E}-05$ \\
\hline 11 & 0.1181 & 0.1184 & $-1.05 \mathrm{E}-04$ & $-9.50 \mathrm{E}-05$ \\
\hline 12 & 0.1172 & 0.1170 & $-1.72 \mathrm{E}-04$ & $-9.10 \mathrm{E}-05$ \\
\hline 13 & 0.1154 & 0.1155 & $-1.81 \mathrm{E}-04$ & $-8.80 \mathrm{E}-05$ \\
\hline 14 & 0.1136 & 0.1141 & $-9.60 \mathrm{E}-05$ & $-8.40 \mathrm{E}-05$ \\
\hline 15 & 0.1133 & 0.1125 & $-1.21 \mathrm{E}-04$ & $-8.10 \mathrm{E}-05$ \\
\hline 16 & 0.1117 & 0.1110 & $-1.51 \mathrm{E}-04$ & $-7.70 \mathrm{E}-05$ \\
\hline 17 & 0.1093 & 0.1096 & 5.77E-06 & $-7.40 \mathrm{E}-05$ \\
\hline 18 & 0.1090 & 0.1081 & $-8.44 \mathrm{E}-06$ & $-7.00 \mathrm{E}-05$ \\
\hline 19 & 0.1068 & 0.1068 & $-3.00 \mathrm{E}-05$ & $-6.70 \mathrm{E}-05$ \\
\hline 20 & 0.1033 & 0.1055 & $6.97 \mathrm{E}-05$ & $-6.30 \mathrm{E}-05$ \\
\hline 21 & 0.1030 & 0.1044 & $-1.36 \mathrm{E}-04$ & $-6.00 \mathrm{E}-05$ \\
\hline 22 & 0.1045 & 0.1033 & $-1.21 \mathrm{E}-04$ & $-5.60 \mathrm{E}-05$ \\
\hline 23 & 0.1027 & 0.1024 & $-6.50 \mathrm{E}-05$ & $-5.30 \mathrm{E}-05$ \\
\hline 24 & 0.0973 & 0.1015 & $-1.01 \mathrm{E}-05$ & $-4.90 \mathrm{E}-05$ \\
\hline 25 & 0.0971 & 0.1008 & $-1.08 \mathrm{E}-04$ & $-4.60 \mathrm{E}-05$ \\
\hline 26 & 0.0991 & 0.1002 & $6.80 \mathrm{E}-06$ & $-4.20 \mathrm{E}-05$ \\
\hline 27 & 0.0968 & 0.0997 & $-7.89 \mathrm{E}-06$ & $-3.90 \mathrm{E}-05$ \\
\hline 28 & 0.0970 & 0.0992 & $-2.24 \mathrm{E}-05$ & $-3.50 \mathrm{E}-05$ \\
\hline 29 & 0.0976 & 0.0988 & $-1.04 \mathrm{E}-05$ & $-3.20 \mathrm{E}-05$ \\
\hline 30 & 0.0978 & 0.0985 & $-4.33 \mathrm{E}-05$ & $-2.80 \mathrm{E}-05$ \\
\hline 31 & 0.0947 & 0.0981 & $-1.88 \mathrm{E}-05$ & $-2.50 \mathrm{E}-05$ \\
\hline 32 & 0.0973 & 0.0978 & $-2.35 \mathrm{E}-05$ & $-2.10 \mathrm{E}-05$ \\
\hline 33 & 0.0957 & 0.0974 & $9.13 \mathrm{E}-06$ & $-1.80 \mathrm{E}-05$ \\
\hline 34 & 0.0945 & 0.0970 & $3.42 \mathrm{E}-05$ & $-1.40 \mathrm{E}-05$ \\
\hline 35 & 0.0964 & 0.0966 & $-2.40 \mathrm{E}-05$ & $-1.10 \mathrm{E}-05$ \\
\hline 36 & 0.0947 & 0.0962 & $-6.46 \mathrm{E}-06$ & $-7.00 \mathrm{E}-06$ \\
\hline 37 & 0.0947 & 0.0957 & $-1.56 \mathrm{E}-05$ & $-4.00 \mathrm{E}-06$ \\
\hline 38 & 0.0949 & 0.0952 & 3.49E-05 & 0 \\
\hline
\end{tabular}


Table 3: Comparison between theoretical calculations for $\mathrm{N}_{2}$-broadening coefficients (in $10^{-3}$ $\mathrm{cm}^{-1} \cdot \mathrm{atm}^{-1}$ ) obtained for the $v_{1}$ and the pure rotational bands (for $K$ equal 3 and $J \leq 40$ ).

\begin{tabular}{ccc}
\hline$J$ & pure rotational & \\
band & $v_{1}$ band \\
3 & 113.81 & 113.81 \\
4 & 119.41 & 119.41 \\
5 & 121.53 & 121.53 \\
6 & 122.44 & 122.44 \\
7 & 122.71 & 122.72 \\
8 & 122.53 & 122.53 \\
9 & 121.95 & 121.96 \\
10 & 121.00 & 121.01 \\
11 & 119.72 & 119.73 \\
12 & 118.14 & 118.16 \\
13 & 116.32 & 116.34 \\
14 & 114.33 & 114.35 \\
15 & 112.26 & 112.28 \\
16 & 110.16 & 110.17 \\
17 & 108.11 & 108.12 \\
18 & 106.17 & 106.18 \\
19 & 104.36 & 104.37 \\
20 & 102.71 & 102.71 \\
21 & 101.21 & 101.22 \\
22 & 99.86 & 99.86 \\
23 & 98.65 & 98.65 \\
24 & 97.56 & 97.56 \\
25 & 96.58 & 96.59 \\
26 & 95.71 & 95.71 \\
27 & 94.93 & 94.93 \\
28 & 94.23 & 94.23 \\
29 & 93.62 & 93.62 \\
30 & 93.10 & 93.10 \\
31 & 92.67 & 92.66 \\
32 & 92.32 & 92.31 \\
33 & 92.06 & 92.05 \\
34 & 91.89 & 91.88 \\
35 & 91.79 & 91.78 \\
36 & 91.77 & 91.75 \\
37 & 91.79 & 91.78 \\
38 & 91.85 & 91.84 \\
39 & 91.94 & 91.92 \\
40 & 92.03 & 92.01 \\
\hline & & \\
& &
\end{tabular}


Table 4:Sample of measured and calculated $\mathrm{N}_{2}$-broadening coefficients for the $v_{1}$ band.

\begin{tabular}{|c|c|c|c|c|c|c|c|c|c|c|}
\hline \multicolumn{7}{|c|}{ Assignment } & \multirow[t]{2}{*}{ Position } & \multirow[t]{2}{*}{$\gamma_{N_{2}}$} & \multirow[t]{2}{*}{$\gamma_{N_{2} e m p}$} & \multirow[t]{2}{*}{$\gamma_{N_{2} \text { theo }}$} \\
\hline ISO & \multicolumn{3}{|c|}{ Upper state } & \multicolumn{3}{|c|}{ Lower state } & & & & \\
\hline 242 & $\overline{7}$ & $\overline{1}$ & $\bar{E}$ & 6 & $\overline{1}$ & $\bar{E}$ & 2973.80671 & 0.120 & 0.124 & 0.124 \\
\hline 241 & 7 & 1 & $\mathrm{E}$ & 6 & 1 & $\mathrm{E}$ & 2973.92316 & 0.123 & $\odot .124$ & 0.124 \\
\hline 242 & 7 & 2 & E & 6 & 2 & $E$ & 2973.63957 & 0.122 & $\odot .124$ & 0.123 \\
\hline 242 & 5 & 3 & A & 6 & 3 & A & 2962.01191 & 0.128 & 0.122 & $\odot .122$ \\
\hline 241 & 5 & 3 & A & 6 & 3 & A & 2961.95110 & 0.123 & 0.122 & 0.122 \\
\hline 241 & 7 & 3 & A & 6 & 3 & A & 2973.47840 & 0.120 & 0.122 & 0.122 \\
\hline 242 & 7 & 3 & A & 6 & 3 & A & 2973.36179 & $\odot .121$ & $\odot .122$ & $\odot .122$ \\
\hline 242 & 7 & 4 & E & 6 & 4 & $E$ & 2972.97326 & $\odot .117$ & 0.120 & 0.120 \\
\hline 242 & 7 & 5 & $\mathrm{E}$ & 6 & 5 & $E$ & 2972.47383 & 0.119 & 0.118 & 0.116 \\
\hline 241 & 7 & 6 & $A$ & 6 & 6 & $A$ & 2971.98138 & 0.120 & 0.115 & 0.106 \\
\hline 241 & 39 & $\odot$ & A2 & 40 & $\odot$ & A1 & 2932.58114 & $\odot .094$ & $\odot .095$ & 0.092 \\
\hline 242 & 39 & $\odot$ & $A 2$ & 40 & $\odot$ & A1 & 2933.10233 & 0.100 & $\odot .095$ & $\odot .092$ \\
\hline 242 & 39 & 1 & $\mathrm{E}$ & 40 & 1 & $E$ & 2933.05643 & 0.107 & $\odot .095$ & $\odot .092$ \\
\hline 241 & 39 & 1 & $\mathrm{E}$ & 40 & 1 & $\mathrm{E}$ & 2932.53899 & 0.100 & 0.095 & 0.092 \\
\hline 242 & 39 & 2 & $\mathrm{E}$ & 40 & 2 & $E$ & 2932.84369 & $\odot . \odot 99$ & $\odot .095$ & $\odot .092$ \\
\hline 241 & 39 & 2 & E & 40 & 2 & $E$ & 2932.32363 & $\odot . \odot 88$ & $\odot .095$ & $\odot .092$ \\
\hline 242 & 39 & 3 & A & 40 & 3 & A & 2932.59316 & $\odot .097$ & $\odot .095$ & $\odot .092$ \\
\hline 241 & 39 & 3 & A & 40 & 3 & A & 2932.07456 & $\odot .094$ & $\odot .095$ & $\odot .092$ \\
\hline 241 & 39 & 4 & $E$ & 40 & 4 & $\mathrm{E}$ & 2931.69791 & 0.092 & 0.095 & 0.092 \\
\hline 241 & 39 & 5 & $\mathrm{E}$ & 40 & 5 & $E$ & 2931.21973 & 0.100 & $\odot .095$ & $\odot .092$ \\
\hline 241 & 39 & 6 & A & 40 & 6 & A & 2930.61662 & $\odot . \odot 96$ & $\odot .095$ & $\odot .092$ \\
\hline 242 & 39 & 6 & A & 40 & 6 & A & 2931.14761 & 0.103 & $\odot .095$ & $\odot .092$ \\
\hline
\end{tabular}

In Column 1, "241" and " 242 " refer to the $\mathrm{CH}_{3}{ }^{35} \mathrm{Cl}$ and $\mathrm{CH}_{3}{ }^{37} \mathrm{Cl}$ isotopic species, respectively (AFGL notation). Columns 2 to 7 give for the upper and lower states respectively, the $J$ and $K$ rotational quantum numbers and the symmetry type of the levels. Note that "A" stands for overlapping $\mathrm{A}_{1} \leftarrow \mathrm{A}_{2}$ and $\mathrm{A}_{2} \leftarrow \mathrm{A}_{1}$ transitions. Columns 8 give the experimental line positions (in $\mathrm{cm}^{-1}$ ). Columns 9-11 are respectively the measured, calculated by empirical law (see Section 4.1) and calculated

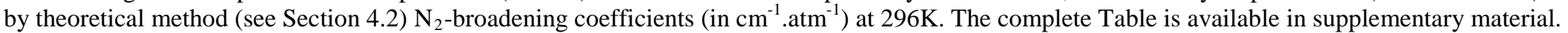


Table 5: Sample of experimental $\mathrm{N}_{2}$-broadening coefficients for the pure rotational band recorded at SOLEIL synchrotron.

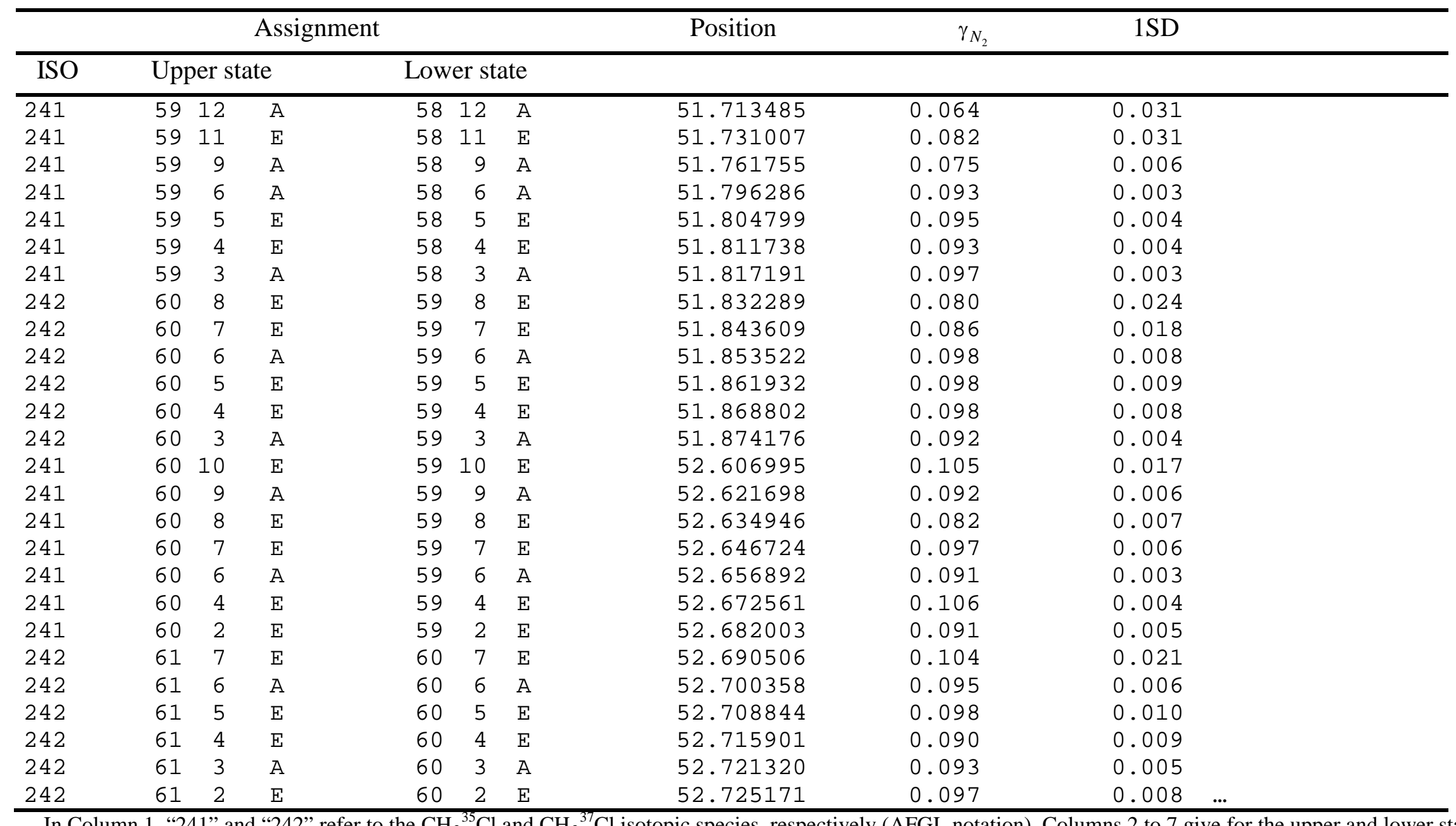

In Column 1, "241" and "242" refer to the $\mathrm{CH}_{3}{ }^{35} \mathrm{Cl}$ and $\mathrm{CH}_{3}{ }^{37} \mathrm{Cl}$ isotopic species, respectively (AFGL notation). Columns 2 to 7 give for the upper and lower states respectively, the $J$ and $K$ rotational quantum numbers and the symmetry type of the levels. Note that "A" stands for overlapping $\mathrm{A}_{1} \leftarrow \mathrm{A}_{2}$ and $\mathrm{A}_{2} \leftarrow \mathrm{A}_{1}$ transitions. Columns 8 give the experimental line positions (in $\mathrm{cm}^{-1}$ ). Column 9 is the measured $\mathrm{N}_{2}$-broadening coefficients $\left(\mathrm{in} \mathrm{cm}^{-1}\right.$.atm ${ }^{-1}$ ) at 296K. 1SD corresponds to the statistical deviation of the fitted broadening coefficients. The complete Table is available in supplementary material. 
Figure 1:

In the upper panel, experimental absorption spectrum (\#8, see Table 1 for experimental conditions) of $\mathrm{CH}_{3} \mathrm{Cl}$ recorded around $55 \mathrm{~cm}^{-1}$ using AILES beamline of SOLEIL synchrotron. This figure gives the $K$-branches for the two isotopologues $\mathrm{CH}_{3}{ }^{35} \mathrm{Cl}$ and $\mathrm{CH}_{3}{ }^{37} \mathrm{Cl}$ for $\mathrm{J}=56$ and 57 respectively. The significant irregular multiplicative channel spectrum can be modeled locally (on a small spectral range of around $0.14 \mathrm{~cm}^{-1}$ ) as a background. In the lower panel, as comparison is presented an experimental absorption spectrum (\#2, see Table 1 for experimental conditions) of $\mathrm{CH}_{3} \mathrm{Cl}$ recorded around $2981 \mathrm{~cm}^{-1}$ in LADIR.
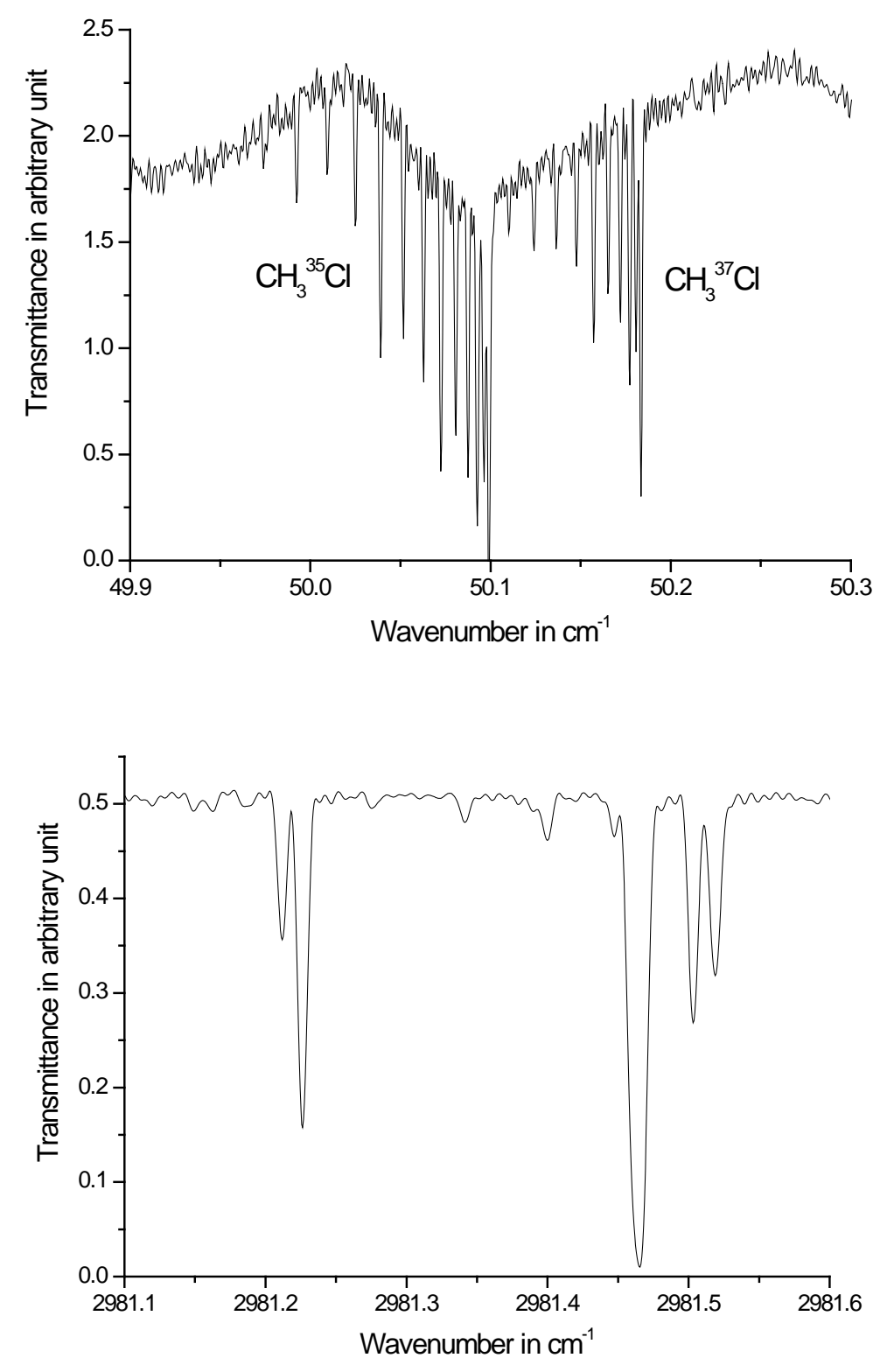
Figure 2:

Comparison between ours results of effective radius of the beam for spectrum \#8 and results for spectrum \#1 from Ref. [19]. In open triangles, results of effective radius of the beam retrieved from water transitions. In solid triangles, results retrieved from water and $\mathrm{C}_{2} \mathrm{H}_{2}$ molecules [19]. The continuous line (see polynomial function in section 3.2.) represents the rotational dependence of the effective radius of the beam used to calculate the apparatus function during the retrieval of broadening parameters. Stars represent the theoretical calculation using SOLEMIO and SRW models [20].

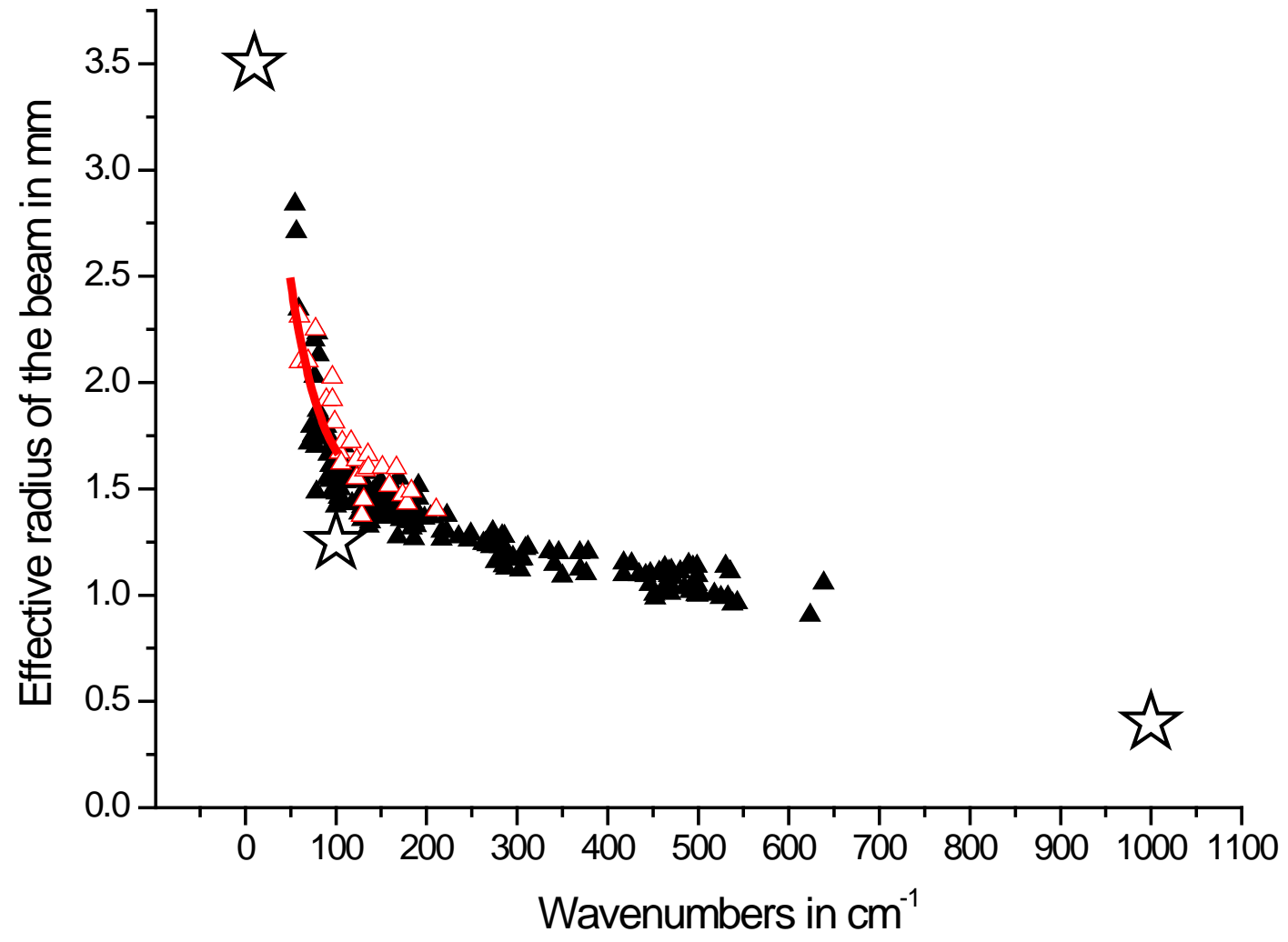


Figure 3:

The upper panel represents an example of the simultaneous fit of two transitions from 7 experimental spectra (from lower to higher pressure, see Table 1) between 2931.17 and $2931.37 \mathrm{~cm}^{-1}$. The lower panel represents an example of the simultaneous fit of 18 transitions from 4 experimental spectra (from lower to higher pressure, see Table 1) between 52.60 and $52.74 \mathrm{~cm}^{-1}$

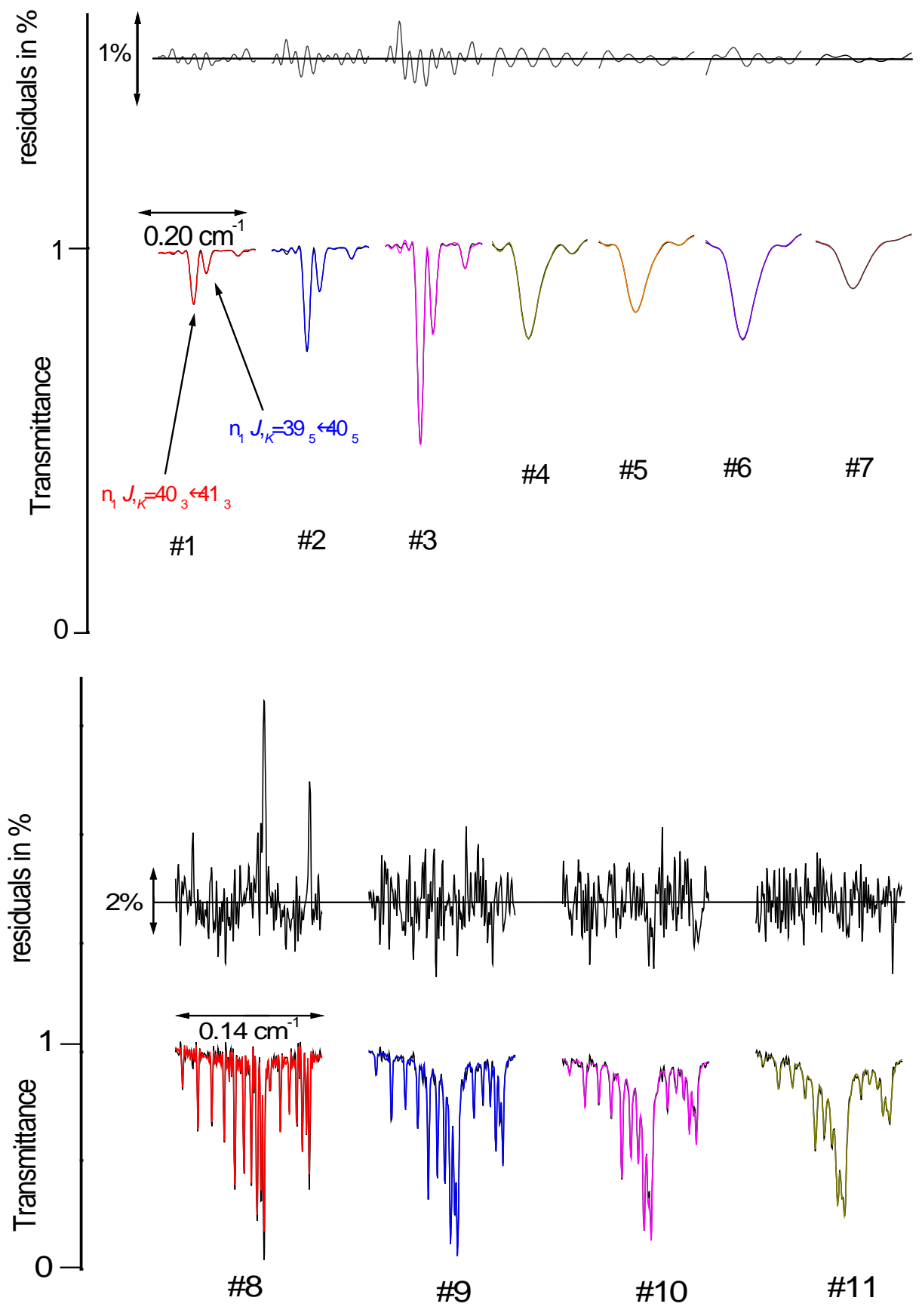


Figure 4:

Experimental $\mathrm{N}_{2}$-broadening coefficients $\gamma_{N_{2}}^{0}$ vs. $K^{2}$ for different $J$ values (4, 10, 19 and 28). The symbols represent the measured $\mathrm{N}_{2}$-broadening coefficients, the solid curve the calculation using the empirical model described in Section 4.1. Error bars corresponds to the statistical deviation (1SD) of the fit of the broadening coefficients.
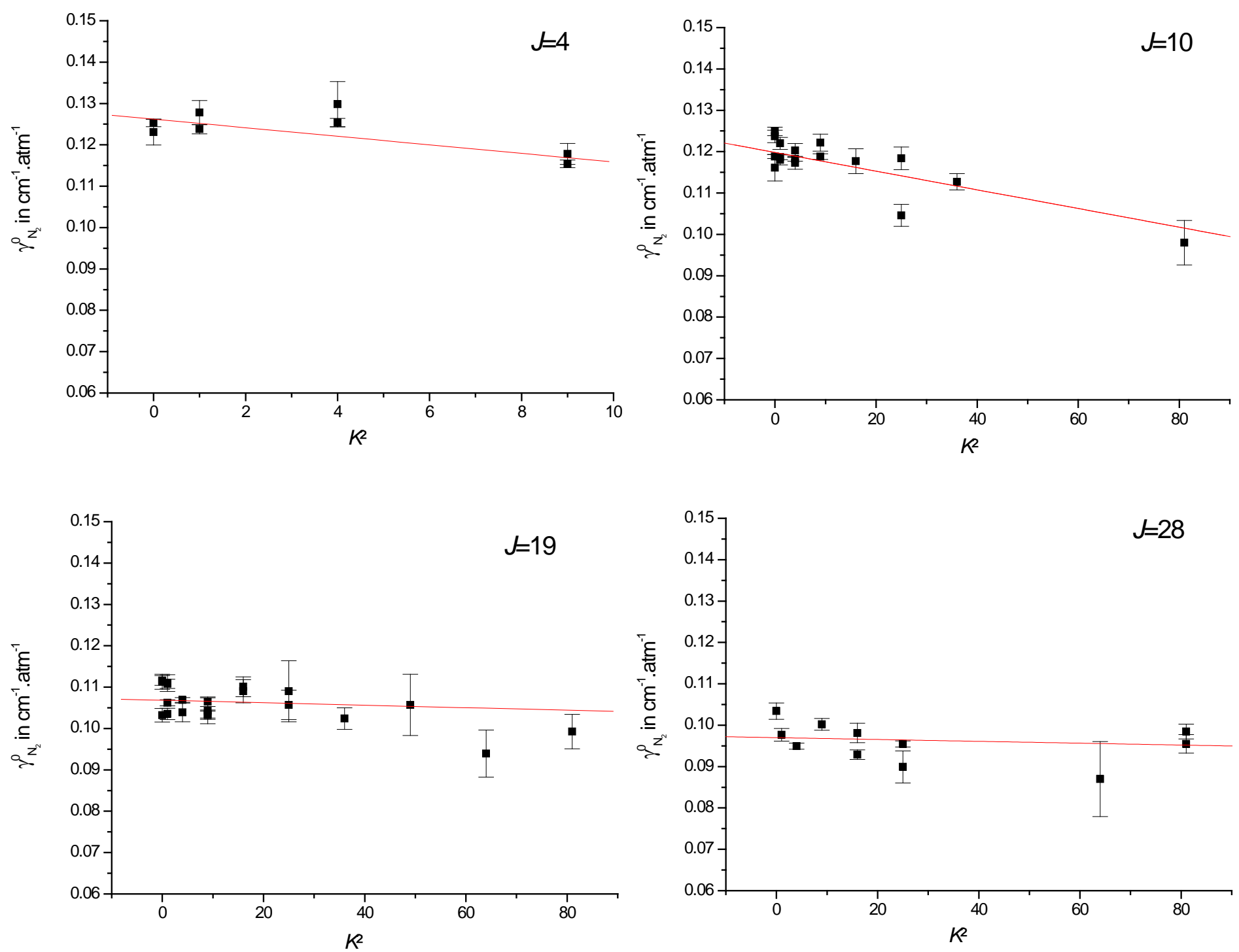
Figure 5:

Parameters $a^{0}{ }_{J}$ deduced from the fit of the measured $\mathrm{N}_{2}$-broadening coefficients using Eq. [2]. The continuous line represents the smoothed values of these coefficients from Table 5 . The error bars are 1 SD.

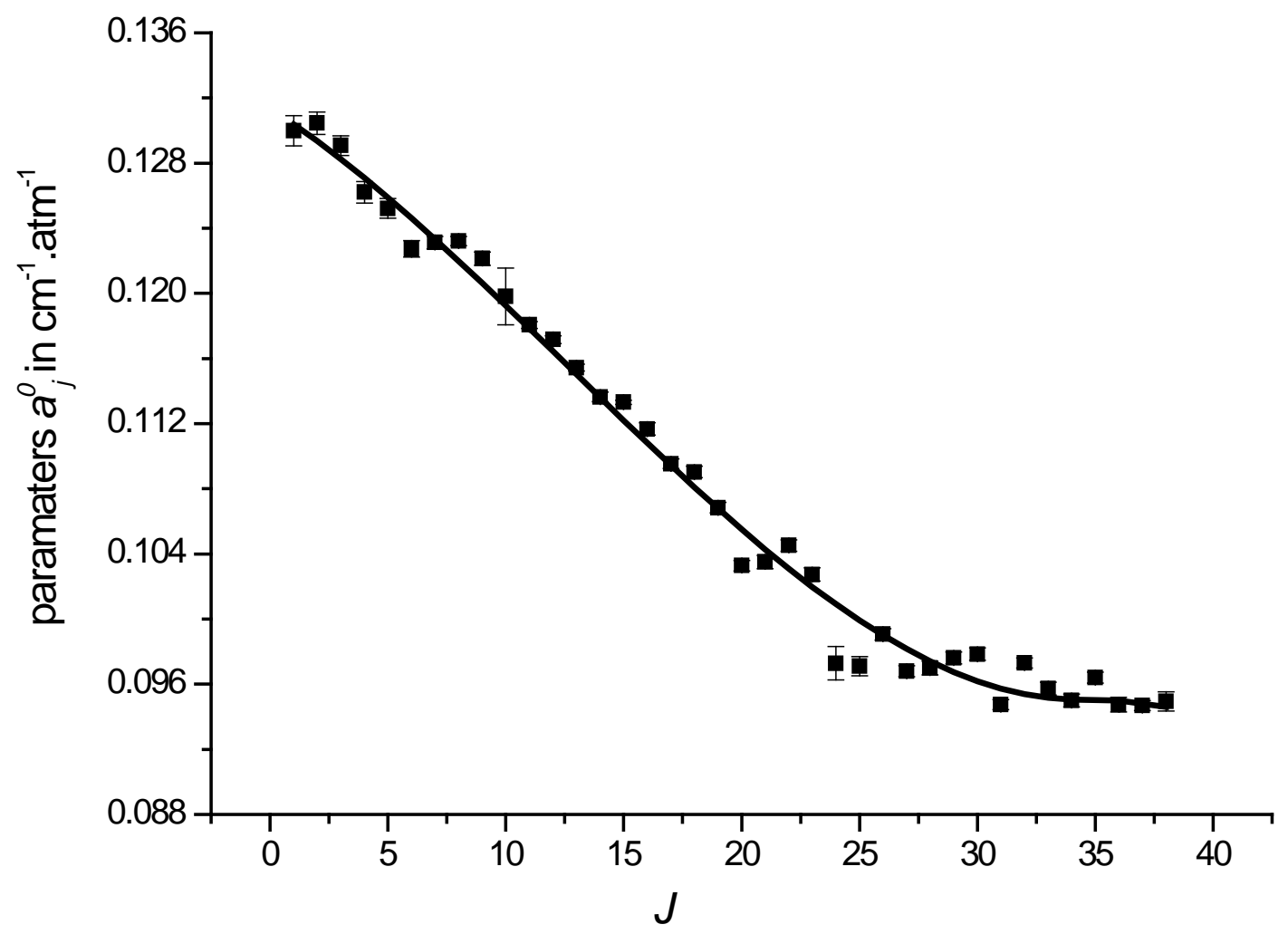


Figure 6:

Parameters $a_{J}^{2}$ deduced from the fit of the measured $\mathrm{N}_{2}$-broadening coefficients using Eq. [2]. The continuous line represents the smoothed values of these coefficients from Table 5 . The error bars are 1 SD.

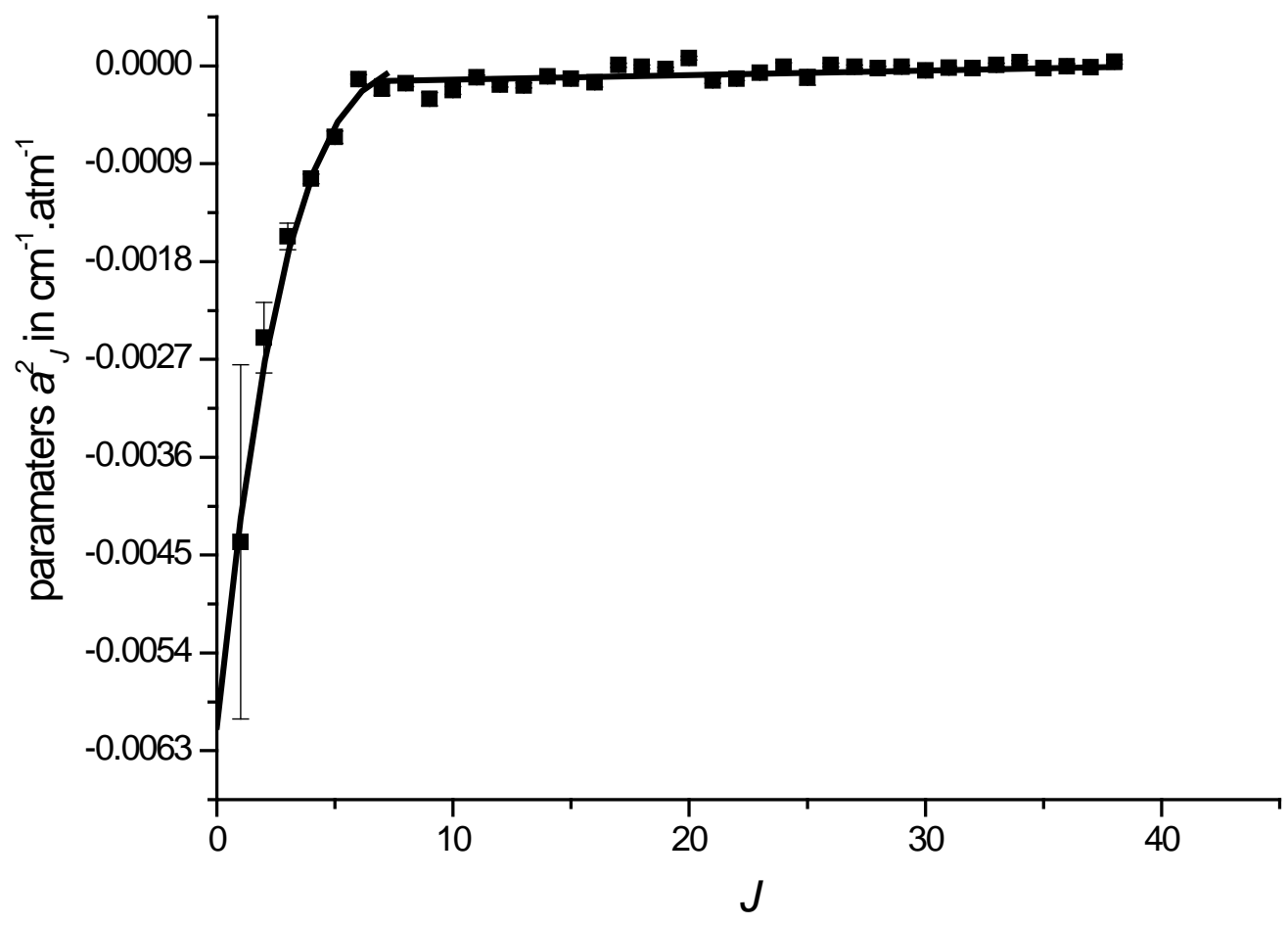


Figure 7:

$K$ dependence of $\mathrm{N}_{2}$-broadening coefficients obtained using the empirical model described in Section 4.1. $\mathrm{N}_{2}$-broadening coefficients are displayed vs. rotational quantum number $J$ for $K$ values from 0 to 9 .

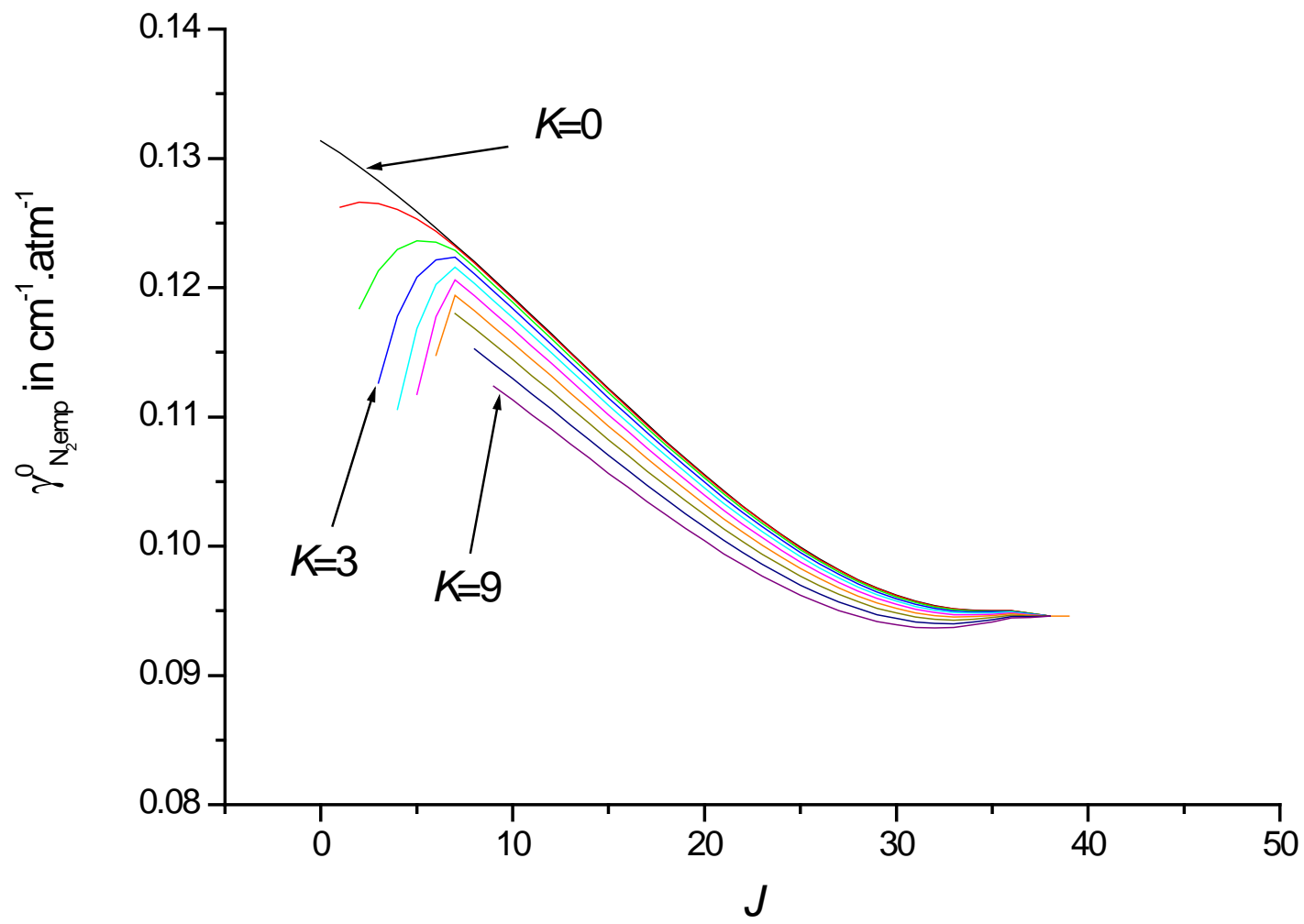


Figure 8:

$J$ and $K$ dependences measured and calculated for $\mathrm{N}_{2}$-broadening coefficients. Black open triangles represent the measured line widths from this work, black continuous line corresponds to the widths modelled by the algorithm described in Section 4.1, and blue continuous line indicates the calculations with the semi-classical method of Section 4.2. Red stars stand for the experimental values obtained in Ref. [9] and red dotted line represents the theoretical calculations from Ref. [9]. Blue solid circles symbolize the experimental values of Ref [8].
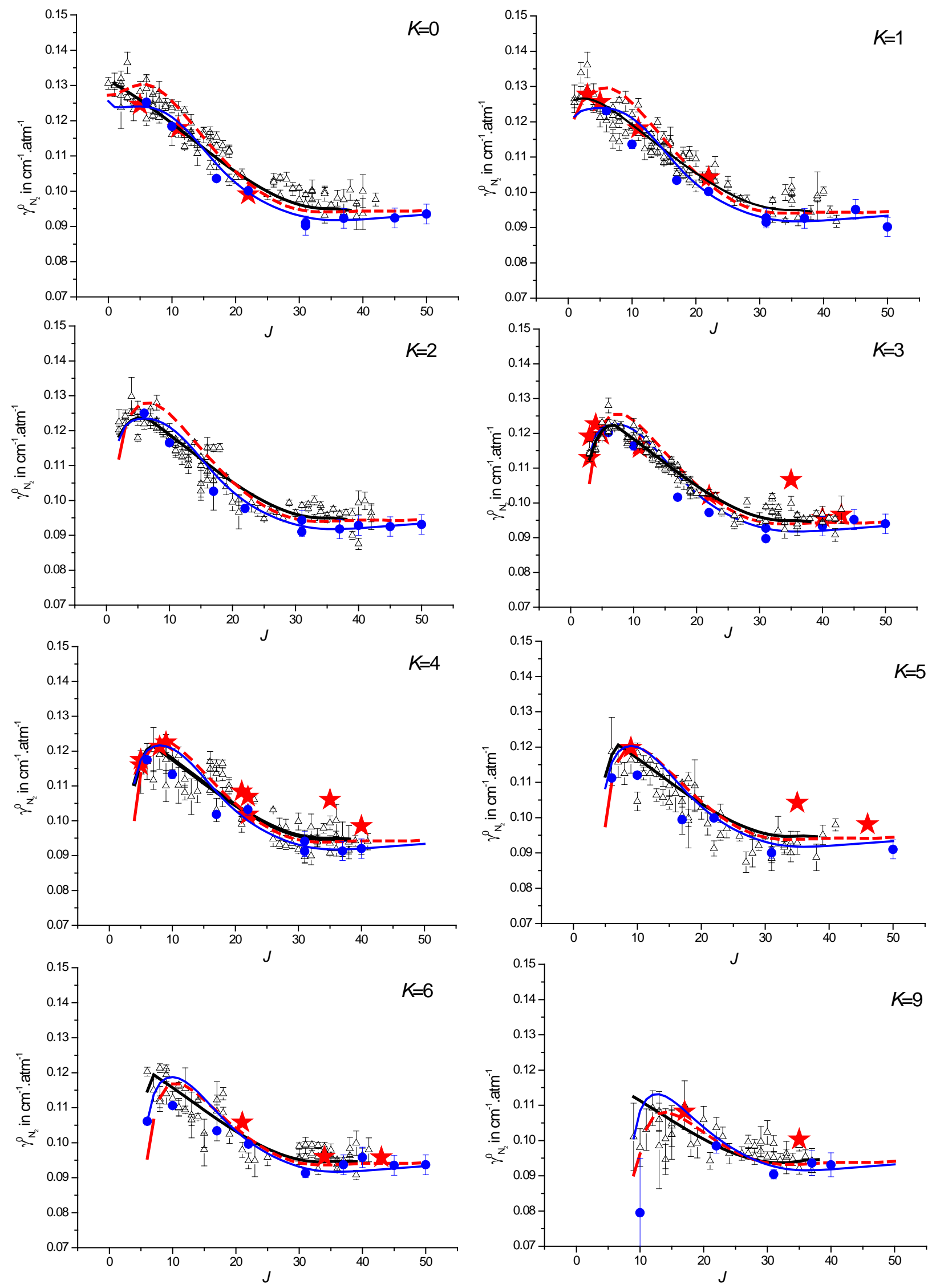
Figure 9:

$\mathrm{N}_{2}$-broadening coefficients measured in the pure rotational band for $J$ values between 55 and 67 and $K$ values between 0 and 12. A large dispersion is present due to low signal-to-noise ratio. The average value (continuous black line) is equal to $(0.092 \pm 0.009) \mathrm{cm}^{-1} \cdot \mathrm{atm}^{-1}$. The red and blue curves represent the values obtained from the theoretical calculation (see Section 4.2) for $J$ values between 53 and 70 and $K$ values equal to 0 and 15 respectively.

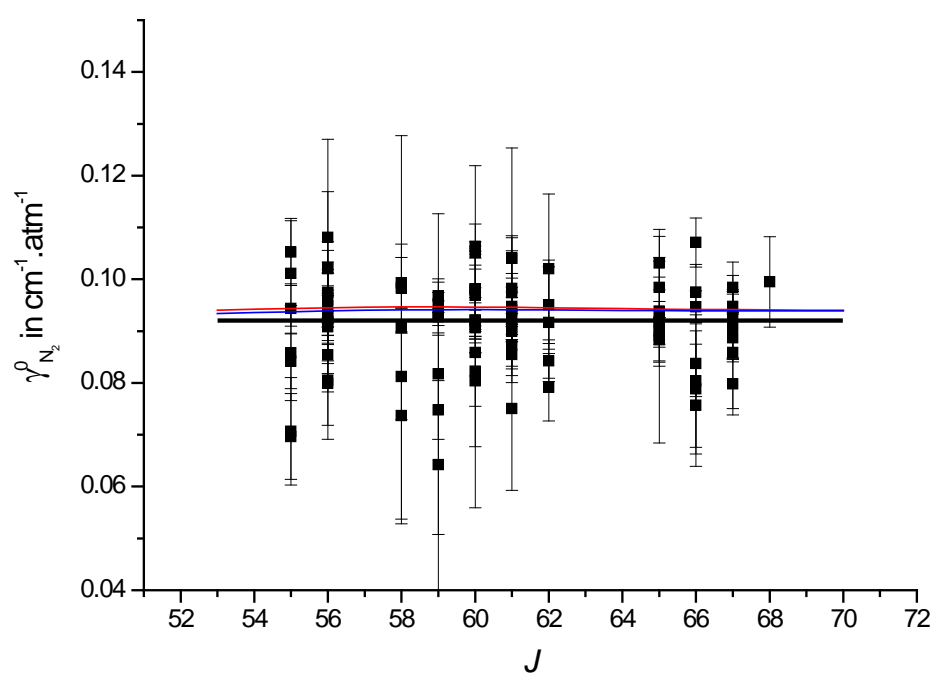

